\title{
Two decades of experience with root remodeling and valve repair for bicuspid aortic valves
}

\author{
Ulrich Schneider, MD, ${ }^{a}$ Susanne K. Feldner, MD, ${ }^{a}$ Christopher Hofmann, ${ }^{a}$ Jakob Schöpe, MSc, ${ }^{b}$ \\ Stefan Wagenpfeil, PhD, ${ }^{b}$ Christian Giebels, MD, ${ }^{a}$ and Hans-Joachim Schäfers, MD $^{\mathrm{a}}$
}

\begin{abstract}
Objective: Bicuspid aortic valve anatomy is associated with ascending aortic aneurysm in approximately $50 \%$ of individuals and may lead to severe aortic regurgitation with aortic dilatation. Both entities may be treated by valve repair and root remodeling. The objective was to review the cumulative experience of 20 years.
\end{abstract}

Methods: Between November 1995 and December 2015, 357 patients (324 male; age 10-80 years; mean, $49 \pm 13$ years) underwent combined bicuspid aortic valve repair and root remodeling. Aortic regurgitation was relevant in 265 cases; the main indications for surgery were aortic regurgitation $(\mathrm{n}=241)$, aortic aneurysm $(\mathrm{n}=102)$, and acute dissection $(\mathrm{n}=9)$. In 225 instances, a suture annuloplasty was added. Cusp calcification was present beyond the raphe in 52 cases, and an autologous pericardial patch was implanted for partial cusp replacement in 39 cases. All patients were followed. Follow-up was $97.8 \%$ complete with a mean of $57 \pm 51$ months (median, 39 months).

Results: Two patients died (hospital mortality $0.6 \%$ ), and survival at 15 years was $81 \%$. Reoperation became necessary for recurrent aortic regurgitation in 24 patients; 6 patients underwent reoperation for stenosis. Cumulative incidence of reoperation at 15 years was $21.7 \%$. Cusp calcification and the use of a pericardial patch for cusp reconstruction were associated with time to reoperation $(P=.002)$.

Conclusions: Repair of the bicuspid aortic valve combined with root remodeling leads to excellent 10- and 15-year results. Cusp calcification and the need for partial cusp replacement are associated with valve failure. (J Thorac Cardiovasc Surg 2017;153:S65-71)

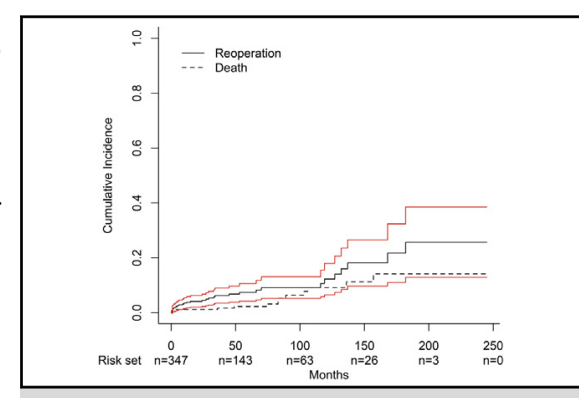

Cumulative incidence for reoperation. Red lines highlight the 95\% confidence interval.

\section{Central Message}

BAV repair and root remodeling lead to excellent long-term stability. Cusp calcification and partial cusp replacement are associated with failure.

\section{Perspective}

A BAV is known to be associated with AR and ascending aortic aneurysm. Both entities may be treated by aortic valve repair and concomitant root remodeling to avoid prosthesis-related complications. In our 20-year experience with this procedure, good long-term results can be achieved in most patients.

See Editorial Commentary page S72.
Bicuspid aortic valve (BAV) anatomy is the most frequent congenital cardiovascular anomaly. ${ }^{1}$ It has been associated with ascending aortic aneurysm in approximately $50 \%$ of affected individuals, ${ }^{2,3}$ which occurs in mainly 2 phenotypes. ${ }^{4}$ It is agreed that patients are at increased risk for aortic dissection and rupture once certain diameters are exceeded, ${ }^{5,6}$ and thus should be treated by aortic

\footnotetext{
From the a Department of Thoracic and Cardiovascular Surgery, Saarland University Medical Center; and ${ }^{\mathrm{b}}$ Institute for Medical Biometry, Epidemiology \& Medical Informatics, Saarland University, Homburg/Saar, Germany.

Read at The American Association for Thoracic Surgery Aortic Symposium, New York, New York, May 12-13, 2016.

Received for publication May 22, 2016; revisions received Dec 9, 2016; accepted for publication Dec 29, 2016; available ahead of print Feb 4, 2017.

Address for reprints: Hans-Joachim Schäfers, MD, Department of Thoracic and Cardiovascular Surgery, Saarland University Medical Center, Homburg/Saar, Germany (E-mail: h-j.schaefers@uks.eu).

$0022-5223 / \$ 36.00$

Copyright (c) 2017 by The American Association for Thoracic Surgery

http://dx.doi.org/10.1016/j.jtcvs.2016.12.030
}

replacement. This will often have to involve the root, at least if root diameter exceeds $45 \mathrm{~mm} .{ }^{5}$ Surgery may be indicated for relevant aortic regurgitation $(\mathrm{AR})^{7}$ and should probably include aortic replacement if there is concomitant aortic dilatation.

Traditional surgical therapy has been the composite replacement of the valve and aorta using a mechanical or biologic prosthesis. We have previously proposed root remodeling with concomitant BAV repair for this purpose. ${ }^{8}$ Root replacement with concomitant aortic valve repair has been shown to be beneficial for patients with somewhat lesser degrees of aortic dilatation but severe AR. ${ }^{9}$ This may

Scanning this QR code will take you to a video for the article. 


\section{Abbreviations and Acronyms \\ $\mathrm{AR}=$ aortic regurgitation \\ $\mathrm{BAV}=$ bicuspid aortic valve \\ $\mathrm{HR}=$ hazard ratio}

be due to mechanical stabilization of the root in the presence of annular dilatation; remodeling also allows for changing commissural orientation into a more symmetric one. ${ }^{10}$ Despite concerns of others over limitations of the function of a BAV, ${ }^{11}$ we have continued to use the concept for more than 20 years with only limited technical modifications.

The objective of the current analysis was to review the cumulative experience of 20 years with this approach, focusing on late function of the aortic valve. In particular, we attempted to determine predictors for reoperation and to analyze whether suture annuloplasty or commissural orientation had an influence on late valve function.

\section{MATERIAL AND METHODS}

Of 852 individuals treated by root remodeling between November 1995 and December 2015 at Saarland University Medical Center, 357 patients were treated for aortic pathology in the presence of a BAV (Figure 1). They are the subject of the current analysis. All patients gave their consent, and the regional ethics committee approved the study and publication of data in anonymized fashion.

The age ranged from 10 to 80 years (mean, $49 \pm 13$ years; median, 49 years), and 324 were male. The aortic pathology was aneurysm in 348 patients and acute aortic dissection type A in 9 patients. The degree of preoperative AR ranged from trace to IV, with relevant AR ( $\geq \mathrm{III})$ being present in $74 \%$ (Table 1 ). The primary indication for surgery was AR $(n=241)$, aortic aneurysm $(n=102)$, acute dissection $(n=9)$, coronary artery disease $(\mathrm{n}=3)$, mitral regurgitation $(\mathrm{n}=1)$, and subaortic stenosis $(\mathrm{n}=1)$. Left ventricular end-diastolic diameter ranged from 36 to $93 \mathrm{~mm}$ (mean, $59 \pm 9 \mathrm{~mm}$ ). Concomitant cardiac disease was present in 105 patients (Table 1). In the majority of cases, right/left fusion was seen ( $\mathrm{n}=310 ; 87 \%)$; fusion of right and noncoronary cusps was present in 44 patients (12\%), and left/noncoronary fusion was present in 3 patients $(0.8 \%)$. Fusion was complete in 268 patients $(75 \%)$ and partial in 89 patients $(25 \%)$. The diameter of the basal ring varied from 23 to $40 \mathrm{~mm}$ (mean, $31 \pm 4 \mathrm{~mm}$ ).

\section{Surgical Technique}

The surgical technique remained generally constant over time and has been described. ${ }^{8-10}$ All procedures were performed via a median sternotomy with aortic and right atrial cannulation. In acute dissection, the right axillary artery was used for arterial inflow. Antegrade blood cardioplegia was given for myocardial protection. A Dacron graft was tailored to accommodate the characteristics of the bicuspid root. Graft size was chosen according to body surface area of the patient, with $22 \mathrm{~mm}(\mathrm{n}=5)$ or $24 \mathrm{~mm}(\mathrm{n}=59)$ for less than $2 \mathrm{~m}^{2} 26 \mathrm{~mm}$ for 2 to $2.2 \mathrm{~m}^{2}(\mathrm{n}=273)$, and $28 \mathrm{~mm}(\mathrm{n}=20)$ for body surface area greater than $2.2 \mathrm{~m}^{2}$. In the first 119 patients, the commissures of the nonfused cusp were placed at a $160^{\circ}$ orientation. In the subsequent 238 patients, an orientation of approximately $180^{\circ}(\mathrm{n}=214)$ was chosen. In the instances with original orientation of less than $140^{\circ}$, a more tricuspid configuration was created at approximately $120^{\circ}(\mathrm{n}=24)$.

In the initial 58 procedures, valve repair was eyeballed, assuming the nonfused cusp as reference for prolapse correction of the fused cusp. Since
2004, the configuration of the nonfused cusp has been ascertained by determining the effective height. ${ }^{12}$ If this was less than $9 \mathrm{~mm}(\mathrm{n}=261)$, prolapse was assumed and central plication sutures were applied to achieve an effective height of 9 to $10 \mathrm{~mm}$. The fused cusp was aligned with the nonfused; prolapse was then treated by central plication sutures $(n=226)$. Triangular resection of raphe tissue was performed in the presence of dense fibrosis or calcification $(\mathrm{n}=83)$. The fused cusp was augmented by an autologous pericardial patch if the extent of triangular resection did not allow for direct approximation of cusp tissue $(n=22)$ or in case of cusp retraction $(n=5)$. Autologous patch insertion was used for closure of perforations $(n=2)$ or fenestrations $(\mathrm{n}=10)$. In 132 procedures, no annular stabilization was added; in these, subcommissural plication was added in 10 procedures. Since 2009, a suture annuloplasty has been added $(\mathrm{n}=225)$ using braided polyester $(n=50)$ or expanded polytetrafluoroethylene $(n=175)$. It was tied around a $23-\mathrm{mm}(\mathrm{n}=55)$ or $25-\mathrm{mm}(\mathrm{n}=170)$ Hegar dilator. The concomitant procedures usually were performed first, to be followed by root replacement. Since 2004, repair of the BAV has been performed after root remodeling was completed (Video 1).

\section{Follow-up}

All patients underwent intraoperative transesophageal echocardiography (Sequoia; GE, Boston, Mass). Postoperatively, all patients were studied before discharge, at 3 months, at 1 year, and yearly thereafter. Systolic aortic valve function was determined using continuous-wave Doppler. Peak and mean systolic gradients were determined. Diastolic function was determined by continuous-wave and color Doppler with semiquantification of AR as I, II, II, or IV. ${ }^{13}$ First occurrence of AR grade I, II, or III was defined as the event when it was diagnosed for the first time.

\section{Statistical Analysis}

Descriptive statistics are presented as mean \pm standard deviation. The date of first occurrence of AR grade I, II, or III was recorded for time-toevent calculation. Differences between continuous variables were compared by analyses of variance with post hoc testing by the Scheffé test. Categoric data were compared using the chi-square test. Cumulative incidences for reoperation, aortic stenosis (both accounted for mortality), and AR grade II (accounted for mortality, AR I, and AR III) were estimated in the framework of competing risks. Associations of effective height measurement (no vs yes), primary indication (AR vs aneurysm), graft size ( $26 \mathrm{~mm}$ vs $24 / 28 \mathrm{~mm}$ ), degree of fusion (partial vs complete), calcification (no vs yes), use of a pericardial patch (no vs yes), and annuloplasty (no vs yes) with respect to time to reoperation were assessed in the framework of competing risks. ${ }^{14,15}$ All models were adjusted for the patient's age, sex (male vs female), degree of fusion (complete vs partial), and presence of calcium (yes vs no) unless otherwise stated. All data were analyzed using IBM SPSS Version 20 and R Version 3.3.1 (cmprsk package) (IBM, New York, NY).

\section{RESULTS}

Duration of myocardial ischemia ranged from 36 to 190 minutes (mean, $70 \pm 16$ minutes) and $67 \pm 13$ minutes for isolated cases without concomitant procedures. Mean time of extracorporeal circulation was $95 \pm 26$ minutes. Two patients died in hospital for a mortality of $0.6 \%$. The causes of death were subarachnoid hemorrhage $(\mathrm{n}=1)$ and stroke $(\mathrm{n}=1)$. Reexploration for hemorrhage was necessary in 5 patients, and in 1 patient, pacemaker implantation for postoperative atrioventricular block was required. Fourteen patients died beyond hospital discharge between 1 and 157 months postoperatively. Of those patients, 8 died of noncardiac reasons, and cardiac 


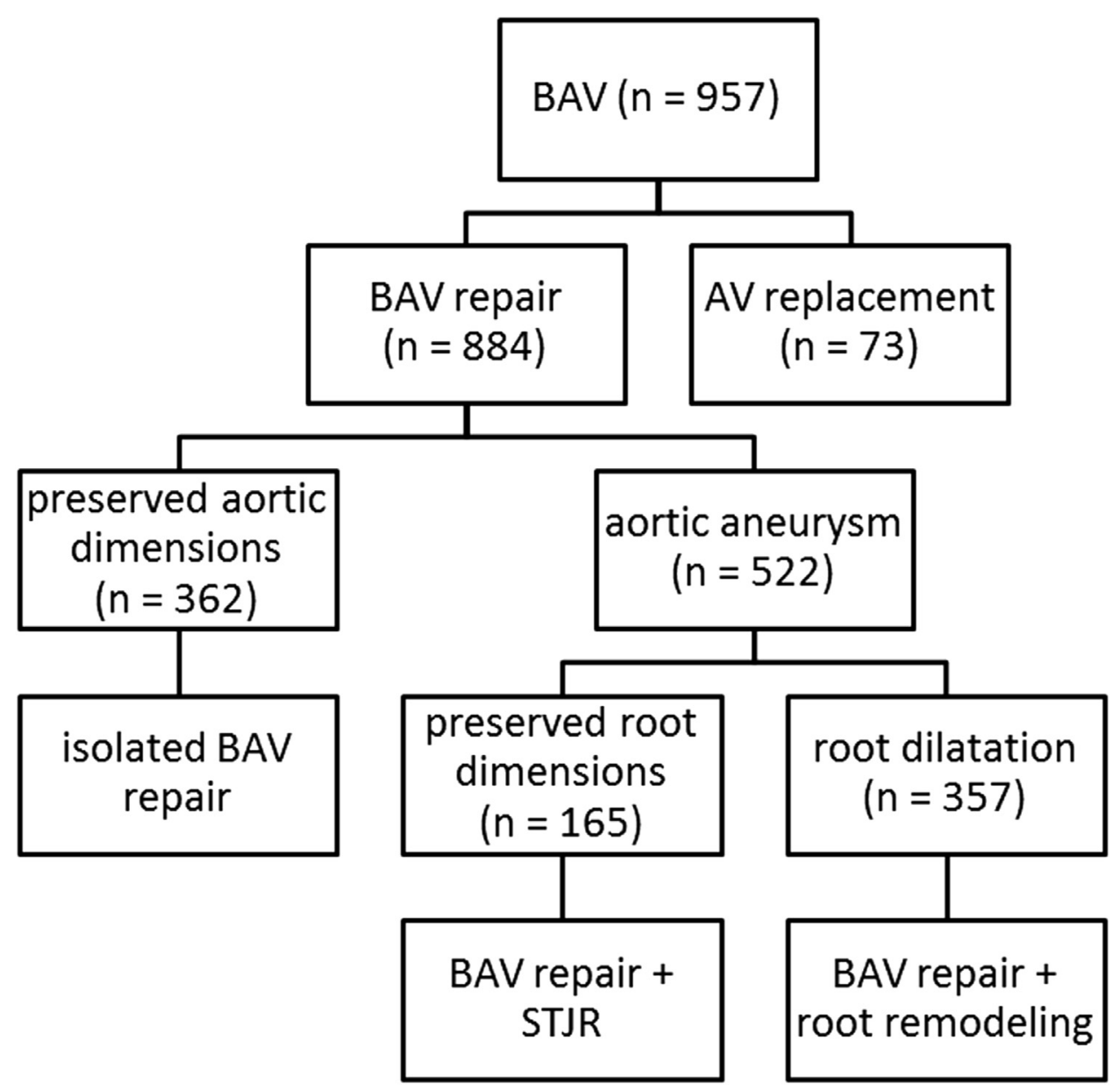

FIGURE 1. CONSORT-style design describing our surgical experience with regurgitant BAVs from November 1995 to December 2015 . BAV, Bicuspid aortic valve; $A V$, aortic valve; STJR, sinotubular junction remodeling.

causes were present in 6 . Survival at 10 and 15 years was $89 \%$ and $81 \%$, respectively.

There was a higher proportion of competent aortic valves at the time of discharge with the use of an annuloplasty $(82.6 \%$ vs $95.6 \% ; P<.001)$. Mean peak gradients ranged from 2 to $40 \mathrm{~mm} \mathrm{Hg}$ with a mean of $11 \pm 6 \mathrm{~mm} \mathrm{Hg}$. There was a difference in peak gradient depending on the postoperative commissural orientation $\left(120^{\circ}: 7.4 \pm 3.8 \mathrm{~mm} \mathrm{Hg}\right.$; $160^{\circ}: 11.4 \pm 6.9 \mathrm{~mm} \mathrm{Hg} ; 180^{\circ}: 11.1 \pm 5.8 \mathrm{~mm} \mathrm{Hg}$ ). The difference between $120^{\circ}$ and $160^{\circ}$ or $180^{\circ}$ was significant $(P<.05)$.

Cumulative incidence of reoperation was $12.3 \%$ at 10 years and $21.7 \%$ at 15 years (Figure 2). Valve function remained constant in the majority of patients. Recurrent AR II developed over time in 37 patients, which progressed to relevant $\mathrm{AR}$ in 21 patients. At 10 and 15 years, the cumulative incidence of AR II was $12.3 \%$ and $17.1 \%$, respectively (Figure 3 ). In 15 patients, an increase of mean systolic gradient was observed over time; this progressed to relevant aortic stenosis in 6 patients requiring reoperation between 66 and 182 months postoperatively. In 3 of these patients, calcium beyond the raphe was present at the time of initial surgery $(5.9 \%)$. In the remaining 3 patients, no calcification had been present $(1.0 \% ; P=.014)$. Cumulative incidence of relevant aortic stenosis after 10 and 15 years was $4.3 \%$ and $8.8 \%$, respectively (Figure 4). Endocarditis was observed and treated conservatively in 2 patients; it required early surgical treatment for progressive infection despite medical treatment in 1 patient. Reoperation became necessary for recurrent AR in 24 patients, as a consequence of endocarditis in 3 .

Adjusted subdistributional hazard ratios (HRs) from multiple regression analysis in the framework of competing risks suggest statistically significant associations of aortic valve calcification (subdistributional HR, 4.34; 95\% confidence interval, 1.69-11.16; $P=.002$ ), and use of a pericardial patch for partial cusp replacement (subdistributional HR, 4.00; 95\% confidence interval, 1.65-9.66; $P=.002$ ) with respect to time to reoperation (Table 2). Cause-specific Cox proportional hazard regression models yielded qualitatively similar results. 
TABLE 1. Perioperative patient data

\begin{tabular}{|c|c|}
\hline $\mathrm{n}$ & 357 \\
\hline Male & $324(90.8 \%)$ \\
\hline Female & $33(9.2 \%)$ \\
\hline Age, y & $49 \pm 13$ \\
\hline \multicolumn{2}{|l|}{ AR preoperatively } \\
\hline$<\mathrm{I}$ & $8(2.2 \%)$ \\
\hline I & $32(9.0 \%)$ \\
\hline II & $52(14.6 \%)$ \\
\hline III & $230(64.4 \%)$ \\
\hline IV & $35(9.8 \%)$ \\
\hline \multicolumn{2}{|l|}{ Fusion } \\
\hline Right/left & $310(86.8 \%)$ \\
\hline Right/non & $44(12.3 \%)$ \\
\hline Left/non & $3(0.8 \%)$ \\
\hline Complete & $268(75.1 \%)$ \\
\hline Partial & $89(24.9 \%)$ \\
\hline \multicolumn{2}{|l|}{ Primary indication } \\
\hline AR & $241(67.5 \%)$ \\
\hline Aneurysm & $102(28.6 \%)$ \\
\hline Acute aortic dissection & $9(2.5 \%)$ \\
\hline Coronary artery disease & $3(0.8 \%)$ \\
\hline Mitral regurgitation & $1(0.3 \%)$ \\
\hline Subvalvular aortic stenosis & $1(0.3 \%)$ \\
\hline LVEDD $(\mathrm{mm})$ & $59 \pm 9$ \\
\hline Annuloplasty & $225(63.0 \%)$ \\
\hline Polyester & $50(22.2 \%)$ \\
\hline PTFE & $175(77.8 \%)$ \\
\hline $23 \mathrm{~mm}$ & $55(24.4 \%)$ \\
\hline $25 \mathrm{~mm}$ & $170(75.6 \%)$ \\
\hline Subcommissural plication & $10(2.8 \%)$ \\
\hline Plication nonfused & $261(73.1 \%)$ \\
\hline \multicolumn{2}{|l|}{ Fused cusp } \\
\hline Central plication & $226(63.3 \%)$ \\
\hline Triangular resection & $83(23.2 \%)$ \\
\hline Patch & $39(10.9 \%)$ \\
\hline \multicolumn{2}{|l|}{ Concomitant procedures } \\
\hline Partial arch replacement & 70 \\
\hline Total arch replacement & 2 \\
\hline CABG & 25 \\
\hline MVR & 5 \\
\hline TVR & 1 \\
\hline $\mathrm{PFO}$ & 3 \\
\hline Ablation & 12 \\
\hline Ductus & 1 \\
\hline Glenn & 1 \\
\hline
\end{tabular}

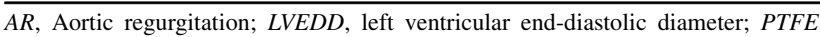
polytetrafluoroethylene; $C A B G$, coronary artery bypass grafting; $M V R$, mitral valve repair; TVR, tricuspid valve repair; $P F O$, patent foramen ovale.

\section{DISCUSSION}

BAV anatomy constitutes a relevant health burden, both due to the valvular complications and the associated aortopathy. ${ }^{1}$ Because of the association of valve dysfunction and aortic dilatation or its consequences, a relevant proportion of affected individuals will require combined treatment of aorta and aortic valve. The affected individuals generally are younger than those who require treatment for acquired

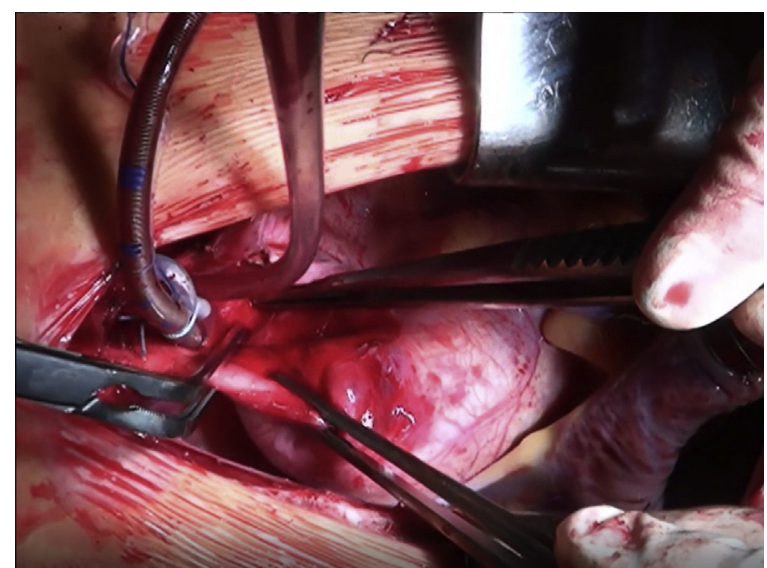

VIDEO 1. On cardiopulmonary bypass, the aorta is crossclamped and incised in a longitudinal fashion. After aortic transection, the stay sutures are placed through the commissures, aortic sinuses are excised, and coronary buttons are preserved. Subsequently, the geometric height of the nonfused cusp is measured to exclude retraction. Direct intubation with a Hegar sizer reveals an enlarged basal ring. A Dacron graft is tailored symmetrically to establish a commissural orientation of $180^{\circ}$. Subsequently, it is sutured to the aortic root following the insertion line of the cusps of the aortic valve. Afterward, a suture annuloplasty is placed around the enlarged basal ring and tied around a graded Hegar dilator. Measuring the effective height of the nonfused cusp reveals prolapse, which is corrected by central plication. Prolapse of the fused cusp is corrected similarly until direct comparison shows identical height. Finally, the Dacron graft is sutured to the ascending aorta. Intraoperative transesophageal echocardiography shows a competent aortic valve. Video available at: http://www.jtcvsonline.org/ article/S0022-5223(17)30014-4/addons.

aortic valve disease, as shown by the mean of 49 years in the current analysis. This has implications on life expectancy, lifestyle, and the long-term consequences of surgery.

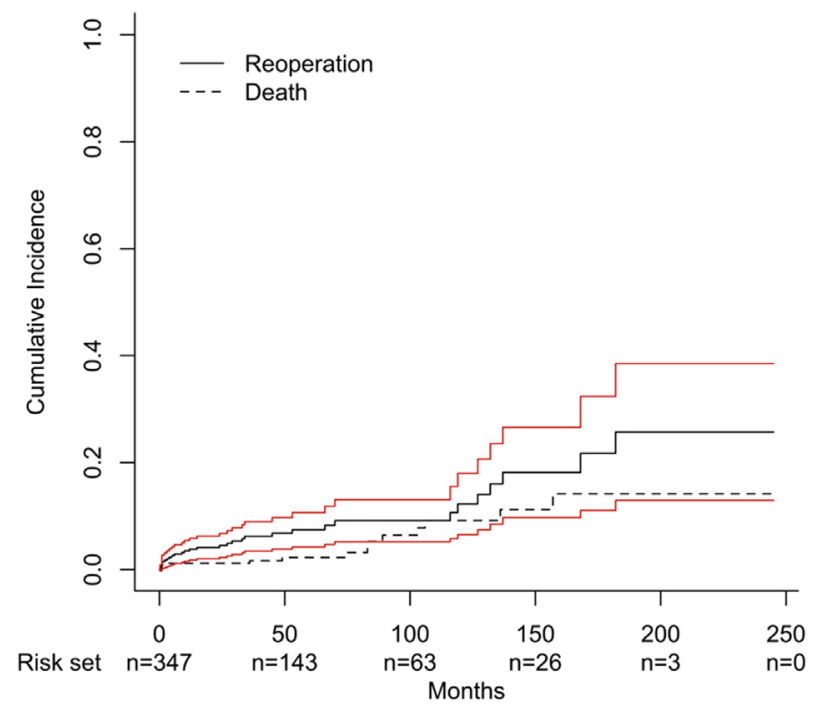

FIGURE 2. Cumulative incidence for reoperation. Red lines highlight the $95 \%$ confidence interval. 


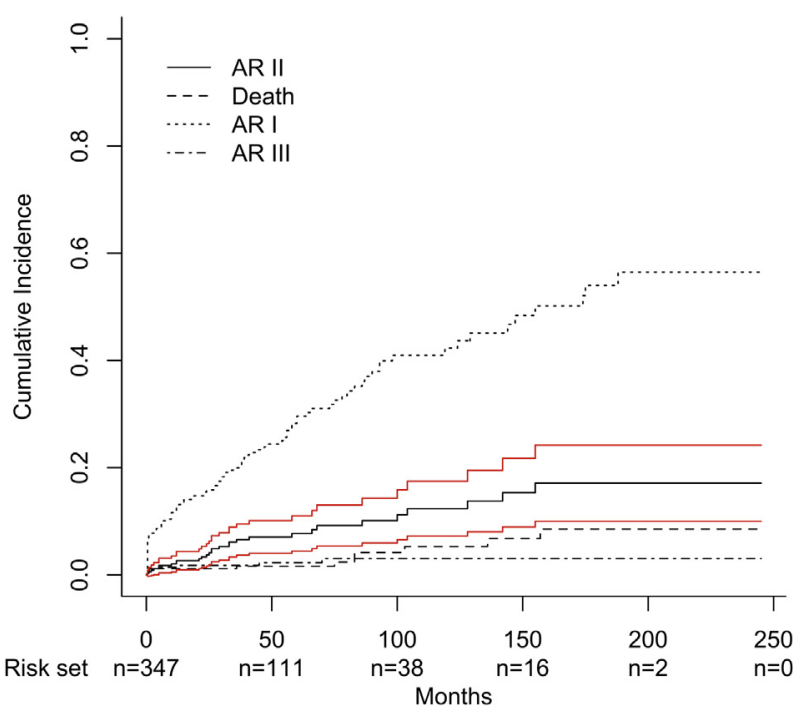

FIGURE 3. Subdistribution cumulative incidence for recurrent AR II (accounted for mortality and occurrence of AR I and AR III). Red lines highlight $95 \%$ confidence interval. $A R$, Aortic regurgitation.

The traditional treatment of combined aortic and valve disease has been replacement of the valve and aorta, as composite replacement, ${ }^{16}$ or, in some instances, as separate valve and aortic replacement. In younger patients, this will imply the use of a mechanical prosthesis with its known valve-related complications. ${ }^{17,18}$ Older patients may be well treated with a biologic substitute; nevertheless, there is an increased risk of prosthetic valve endocarditis, and the limited durability does not make it an ideal choice for younger individuals.

Thus, preservation or repair of the regurgitant BAV seems to be an attractive alternative to replacement. In a retrospective study, ${ }^{19}$ the incidence of valve-related complications

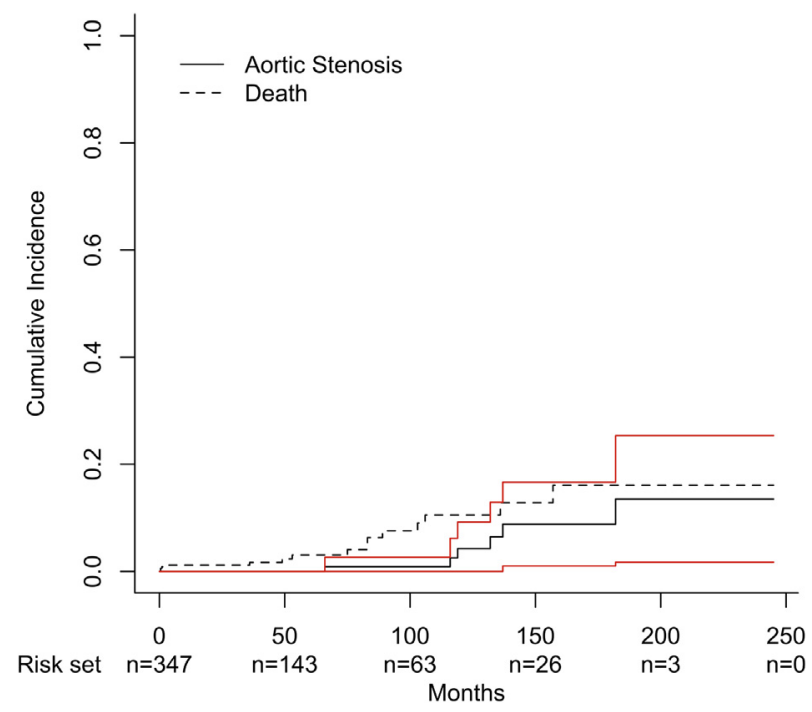

FIGURE 4. Subdistribution cumulative incidence for relevant aortic stenosis (accounted for mortality). Red lines highlight 95\% confidence interval. has been lower compared with other investigations of valve replacement. On the other hand, repair commonly leaves the BAV in its bicuspid form and only corrects the secondary deformations that occurred over time. Conversion of the BAV into a tricuspid aortic valve has been limited in its applicability and midterm durability. ${ }^{20}$ Repair has been associated with limited durability, in part related to anatomic factors. ${ }^{9}$ Finally, it has been proposed that the bicuspid valve will fail because of its design, and the only question would be at what point in time it would require replacement. ${ }^{11}$

We have initially been stimulated by the early results of Cosgrove and colleagues ${ }^{21}$ in repairing the BAV with good results. To treat the combination of root dilatation and $\mathrm{BAV}$, we have combined the principles of aortic valve repair and root remodeling, modifying the established technique of root remodeling to accommodate the anatomic characteristics of the root in $\mathrm{BAV}^{8}$ In the first 10 years, we tried to imitate the given commissural orientation, in most instances with an angle of the nonfused commissures of $160^{\circ} .^{22}$ The initial results were positive; however, we did learn through failures that cusp prolapse may be induced by reducing intercommissural distance as part of aortic replacement. ${ }^{23}$ Valve function was markedly improved with the introduction of the effective height concept. ${ }^{12,24}$ On the basis of excellent midterm stability for BAV repair combined with root remodeling, ${ }^{9}$ this approach is chosen whenever the root exceeds 42 to $45 \mathrm{~mm}$. Thus, we are slightly more aggressive than current guidelines ${ }^{5}$ with the indication for root replacement.

Further experience showed that valve durability in bicuspid valves was influenced by commissural orientation. ${ }^{9}$ This stimulated us to change commissural orientation as part of root replacement by creating 2 symmetric tongues, thus moving toward a $180^{\circ}$ orientation in the majority of cases. We have recently found that this change in commissural orientation may improve not only durability but also systolic gradients in isolated aortic valve repair. ${ }^{25}$ This concept may not be ideal when the original orientation is less than $140^{\circ}$; in this setting, the tissue of the nonfused cusp probably does not allow creation of a close to symmetric BAV. Therefore, we have started to explore an orientation that resembles a tricuspid aortic valve in the past years. Because annular dilatation was a risk factor for failure in our early experience with BAV repair, we also added a suture annuloplasty to root replacement. ${ }^{26}$ The early results of this modified approach were promising in that the proportion of completely competent aortic valves could be increased significantly. ${ }^{27}$ Although no negative consequences of this modification were observed with polytetrafluoroethylene as annuloplasty material, the question remains whether the addition of an annuloplasty improves valve durability. In addition, it is unclear whether an improvement in systolic aortic valve function through a 
TABLE 2. Competing risks regression models

\begin{tabular}{|c|c|c|c|c|c|c|}
\hline & \multicolumn{3}{|c|}{ Crude model } & \multicolumn{3}{|c|}{ Adjusted model } \\
\hline & Subdistributional HR & $P$ value & $95 \% \mathrm{CI}$ & Subdistributional HR & $P$ value & $95 \% \mathrm{CI}$ \\
\hline $\begin{array}{l}\text { Effective height } \\
\text { measurement } \dagger\end{array}$ & 1.62 & .240 & $0.73-3.63$ & 1.23 & .680 & $0.46-3.27$ \\
\hline Aneurysm $\ddagger$ & 0.49 & .083 & $0.22-1.10$ & 0.53 & .130 & $0.24-1.20$ \\
\hline Graft size $\S(24 \mathrm{~mm})$ & 1.14 & .760 & $0.49-2.65$ & 1.22 & .670 & $0.49-3.03$ \\
\hline Graft size $\S(28 \mathrm{~mm})$ & 1.58 & .480 & $0.44-5.72$ & 1.34 & .690 & $0.32-5.65$ \\
\hline Degree of fusion $\|$ & 0.59 & .220 & $0.25-1.39$ & 0.38 & .034 & $0.15-0.93$ \\
\hline Calcification Ø & 2.31 & .030 & $1.08-4.94$ & 4.34 & .002 & $1.69-11.16$ \\
\hline Pericardial Patch\# & 5.17 & $<.001$ & $2.28-11.7$ & 4.00 & .002 & $1.65-9.66$ \\
\hline Annuloplasty*** & 1.55 & .300 & $0.68-3.52$ & 1.21 & .680 & $0.49-2.97$ \\
\hline
\end{tabular}

Competing Risks Regression Models (adjusted for age, calcification* [no/yes], degree of fusion* [no/yes], sex [male/female]). * Only when not considered as investigated independent variable. Bold values indicate statistical significance. $H R$, Hazard ratio; $C I$, confidence interval. $\dagger$ Reference group: no effective height measurement. $\ddagger$ Reference group: AR. §Reference group: graft size $(26 \mathrm{~mm})$. ||Reference group: partial. $\uparrow$ Reference group: no calcification. \#Reference group: no pericardial patch. $* *$ Reference group: no annuloplasty.

more symmetric orientation of the commissures can be achieved if valve repair is combined with root remodeling.

Thus, the objective of the current investigation was to clarify whether long-term aortic valve function can be achieved using BAV repair and root remodeling. In addition, we sought to determine whether commissural orientation and the addition of an annuloplasty have an effect on midterm aortic valve function.

To our knowledge, the current results comprise one of the largest series with root replacement and repair of a BAV in an unselected patient population. The proportion of patients with relevant AR (74\%) was high, and almost all patients required correction of cusp prolapse. Despite the need for concomitant surgery on the aortic arch, coronary arteries, or mitral valve, the early morbidity and mortality were low.

With follow-up now reaching 20 years, we have seen stable aortic valve function in the majority of cases. A cumulative incidence of reoperation of $22 \%$ at 15 years probably translates into a mean durability of more than 20 years, which is better than that of bioprostheses in this age group. If reoperation is necessary, it is technically straightforward and simply consists of excising the native valve and implanting a stented prosthesis. As observed previously, the incidence of endocarditis has been low, that is, $0.3 \%$ per patient per year. The probability of developing relevant aortic stenosis has been low in the first 15 years after repair. With the finding of calcific plaques being a strong predictor for development of later stenosis, patient selection probably should take this aspect into consideration in the future. Despite this concern, many of the valves with some plaques are still functionally adequate, and further careful follow-up will be necessary to determine the exact role of this observation.

Reoperation mostly has been necessary for recurrent regurgitation. We have been particularly impressed by the negative implications of adding an autologous pericardial patch for partial cusp replacement. Although this maneuver is technically not demanding and early results have been good, degeneration (ie, dehiscence or calcification) of the pericardium has occurred in an unpredictable manner. Both the need to use pericardial patch insertion as partial cusp replacement (mostly after excision of a calcified raphe) and the presence of calcific plaques on the cusps beyond the raphe have been the most important predictors of valve failure. Therefore, we currently recommend to abstain from using pericardial patches for partial cusp replacement in BAV repair.

At this time, we have not seen a positive result of the added annuloplasty. Also, the modification of commissural orientation has not yet shown an effect on valve function or durability. Although the symmetric configuration does seem to improve the mobility of the fused cusp, this seems to have no effect on global systolic valve function. Further follow-up will be necessary to analyze these details further.

\section{Study Limitations}

The current analysis does have a number of limitations. It is a single-center study with retrospective analysis, although the data were collected prospectively. We have not attempted to compare the results of remodeling with those of other variants of valve-preserving root replacement in the context of BAV. Thus, we cannot conclude whether remodeling is equal or superior to other techniques. On the other hand, the clinical results have been good, and myocardial ischemia has been lower than what has been reported for valve reimplantation. Further follow-up will be necessary to determine the true long-term results to analyze whether the current trend of valve stability holds true with more individuals beyond 15 years postoperatively. Of the modifications introduced over time, probably the most important was the effective height concept to facilitate correction of valve configuration. The follow-up with these operations now reaches 12 years, and we hope that 15 -year stability will improve when the patients treated in such a way pass the 15-year mark. Longer follow-up will be necessary to investigate the role of the more recent 
modifications, that is, commissural orientation and addition of annuloplasty.

\section{CONCLUSIONS}

Repair of the BAV combined with root remodeling leads to excellent 10- and 15-year results. The durability is good; limited cusp calcification at the time of surgery is associated with an increased risk of developing stenosis within 15 years postoperatively. The need for partial cusp replacement with pericardium is the strongest predictor of valve failure and probably should be avoided in the future.

\section{Conflict of Interest Statement}

Authors have nothing to disclose with regard to commercial support.

\section{References}

1. Ward C. Clinical significance of the bicuspid aortic valve. Heart. 2000;83:81-5.

2. Nistri S, Sorbo MD, Basso C, Thiene G. Bicuspid aortic valve: abnormal aortic elastic properties. J Heart Valve Dis. 2002;11:369-73.

3. Nkomo VT, Enriquez-Sarano M, Ammash NM, Melton LJ III, Bailey KR, Desjardins V, et al. Bicuspid aortic valve associated with aortic dilatation: a community-based study. Arterioscler Thromb Vasc Biol. 2003;23:351-6.

4. Verma S, Siu SC. Aortic dilatation in patients with bicuspid aortic valve. $N$ Engl J Med. 2014:370:1920-9.

5. Erbel R, Aboyans V, Boileau C, Bossone E, Bartolomeo RD, Eggebrecht H, et al. ESC Committee for Practice Guidelines. 2014 ESC Guidelines on the diagnosis and treatment of aortic diseases: document covering acute and chronic aortic diseases of the thoracic and abdominal aorta of the adult. The Task Force for the Diagnosis and Treatment of Aortic Diseases of the European Society of Cardiology (ESC). Eur Heart J. 2014;35:2873-926.

6. Pape LA, Tsai TT, Isselbacher EM, Oh JK, O'gara PT, Evangelista A, et al; International Registry of Acute Aortic Dissection (IRAD) Investigators. Aortic diameter $>$ or $=5.5 \mathrm{~cm}$ is not a good predictor of type A aortic dissection: observations from the International Registry of Acute Aortic Dissection (IRAD). Circulation. 2007:116:1120-7.

7. Vahanian A, Alfieri O, Andreotti F, Antunes MJ, Barón-Esquivias G, Baumgartner H, et al. ESC Committee for Practice Guidelines (CPG); Joint Task Force on the Management of Valvular Heart Disease of the European Society of Cardiology (ESC); European Association for Cardio-Thoracic Surgery (EACTS). Guidelines on the management of valvular heart disease (version 2012): the Joint Task Force on the Management of Valvular Heart Disease of the European Society of Cardiology (ESC) and the European Association for Cardio-Thoracic Surgery (EACTS). Eur J Cardiothorac Surg. 2012;42:S1-44.

8. Schäfers HJ, Langer F, Aicher D, Graeter TP, Wendler O. Remodeling of the aortic root and reconstruction of the bicuspid aortic valve. Ann Thorac Surg. 2000;70:542-6.

9. Aicher D, Kunihara T, Abou Issa O, Brittner B, Gräber S, Schäfers HJ. Valve configuration determines long-term results after repair of the bicuspid aortic valve. Circulation. 2011;123:178-85.
10. Schäfers HJ, Kunihara T, Fries P, Brittner B, Aicher D. Valve-preserving root replacement in bicuspid aortic valves. J Thorac Cardiovasc Surg. 2010;140(6 Suppl):S36-40; discussion S45-51.

11. Robicsek F, Thubrikar MJ, Cook JW, Fowler B. The congenitally bicuspid aortic valve: how does it function? Why does it fail? Ann Thorac Surg. 2004;77:177-85.

12. Schäfers HJ, Bierbach B, Aicher D. A new approach to the assessment of aortic cusp geometry. J Thorac Cardiovasc Surg. 2006;132:436-8.

13. Lancellotti P, Tribouilloy C, Hagendorff A, Moura L, Popescu BA, Agricola E et al. European Association of Echocardiography. European Association of Echocardiography recommendations for the assessment of valvular regurgitation. Part 1: aortic and pulmonary regurgitation (native valve disease). Eur J Echocardiogr. 2010;11:223-44.

14. Fine JP, Gray RJ. A proportional hazards model for subdistribution of a competing risk. J Am Stat Assoc. 1994;94:496-509.

15. Gray B. cmprsk: Subdistribution analysis of competing risks. Available at https://cran.r-project.org/web/packages/cmprsk. Accessed November 29, 2015.

16. Bentall $\mathrm{H}$, De Bono A. A technique for complete replacement of the ascending aorta. Thorax. 1968;23:338-9.

17. Hammermeister K, Sethi GK, Henderson WG, Grover FL, Oprian C, Rahimtoola SH. Outcomes 15 years after valve replacement with a mechanical versus a bioprosthetic valve: final report of the Veterans Affairs randomized trial. J Am Coll Cardiol. 2000;36:1152-8.

18. Takkenberg JJ, Puvimanasinghe JP, van Herwerden LA, Eijkemans MJ Steyerberg EW, Habbema JD, et al. Decision-making in aortic valve replacement: bileaflet mechanical valves versus stented bioprostheses. Neth Heart J 2003;11:5-10.

19. Aicher D, Fries R, Rodionycheva S, Schmidt K, Langer F, Schäfers HJ. Aortic valve repair leads to a low incidence of valve-related complications. Eur J Cardiothorac Surg. 2010;37:127-32.

20. Prêtre R, Kadner A, Dave H, Bettex D, Genoni M. Tricuspidisation of the aortic valve with creation of a crown-like annulus is able to restore a normal valve function in bicuspid aortic valves. Eur J Cardiothorac Surg. 2006;29: 1001-6.

21. Cosgrove DM, Rosenkranz ER, Hendren WG, Bartlett JC, Stewart WJ. Val vuloplasty for aortic insufficiency. J Thorac Cardiovasc Surg. 1991;102: $571-7$.

22. Aicher D, Langer F, Kissinger A, Lausberg H, Fries R, Schäfers HJ. Valvesparing aortic root replacement in bicuspid aortic valves: a reasonable option? J Thorac Cardiovasc Surg. 2004;128:662-8.

23. Schäfers HJ, Aicher D, Langer F, Lausberg HF. Preservation of the bicuspid aortic valve. Ann Thorac Surg. 2007;83:S740-5; discussion S785-90.

24. Bierbach BO, Aicher D, Issa OA, Bomberg H, Gräber S, Glombitza P, et al Aortic root and cusp configuration determine aortic valve function. Eur J Cardiothorac Surg. 2010;38:400-6.

25. Schneider U, Schmied W, Aicher D, Giebels C, Winter L, Schäfers HJ. Sinus plication to improve valve configuration in bicuspid aortic valve repair-early results. Ann Thorac Surg. 2017;103:580-5.

26. Schneider U, Aicher D, Miura Y, Schäfers HJ. Suture annuloplasty in aortic valve repair. Ann Thorac Surg. 2016;101:783-5.

27. Aicher D, Schneider U, Schmied W, Kunihara T, Tochii M, Schäfers HJ. Early results with annular support in reconstruction of the bicuspid aortic valve. J Thorac Cardiovasc Surg. 2013;145(3 Suppl):S30-4.

Key Words: bicuspid aortic valve, aortic valve repair, aortic root replacement, root remodeling 